\title{
Tele-healthcare system: a robotic drone case study
}

\begin{abstract}
Every country is adopting various strategies against the spread and mitigation of the effects of corona disease. Many of the countries of world have gone under complete lockdown. The future strategies use of science, technology, innovation and industrial solutions will play an important role in post pandemic development and re-strengthening of the nation's economy. Health is an important and basic requirement of every human being. During pandemic times the word has realized the shortage and inadequacy of healthcare facilities. It is estimated that post COVID-19 world will reorient its focus from manufacturing nuclear weapons and arms towards development of life-saving equipments, research and technology. The future is indicating and demanding improvement in health care facilities. This paper presents a case of robotic drone based tele-healthcare system for post pandemic era. It depicts how entrepreneurial alertness can convert any situation into business opportunity. The paper comprehensively documents and analyzes the feasibility model of the proposed robotic drone based tele-healthcare system start-up.
\end{abstract}

Volume 7 Issue 2 - 202I

\section{Kshitij Shinghal, Amit Saxena}

Department of Electronics \& Communication Engineering, A.P.J.

Abdul Kalam Technical University, India

Correspondence: Kshitij Shinghal, Department of Electronics \& Communication Engineering, Moradabad Institute of

Technology, A.P.J.Abdul Kalam Technical University, Moradabad, UP, India, Email kshinghal@gmail.com

Received: April 07, 202। | Published: April 19, 2021

Keywords: tele-health facilities, entrepreneurial alertness, innovation, entrepreneurship, healthcare facilities

\section{Introduction}

The present situation of pandemic has taught a lesson to whole mankind that humans have to look at the way of living life with a new perspective. It is better to be prepared and prepared well than to be defeated. It is important to flow with the present moment, concentrate and focus on positivity of life and suppress unwanted negative thoughts. It is important to involve yourself in some activities that improve your immunity, boost your morale and lessen your stress. This is essential to live a stress free life with peace and ease of mind. This will create an ample requirement of a whole new generation of fitness centers like gymnasiums, spas, wellness centers, meditation centers, health clinics and derivatives of such healthcare facilities. All these healthcare facilities along with existing infrastructure as well as newly developed hospitals, clinics, nursing homes, fitness centers will also require to evolve and develop a resilient model for providing healthcare service. These centers have to be equipped with various medical equipments, healthcare equipments latest technology based disease fighting facilities. Though technological innovation cannot check/stop the occurrence of disease but it can be harmless to mitigate the effect of any future outbreaks of contagious diseases. Here lies the opportunity which the young students/future entrepreneur can convert into a successful start-up with entrepreneurial alertness (Figure 1). ${ }^{1}$

Several studies have suggested that a business opportunity is not created but the individual with keen watch over the situation, creative mind and entrepreneurial alertness can convert any situation into start-up opportunity. For this the individual must be sensitive enough to observe the changes in the environment. He must have a keen sense of information sensing, searching and analysis. This entrepreneurial alertness combined with his personal capabilities like creativity, innovativeness, and his knowledge and experience (direct or acquired) can result in successful start-up. Figure 2 shows model of entrepreneurial alertness. The paper is organized as: the related work is reported in section 2, the methodology for the proposed area described in section 3, point to point analysis of business model of telehealth system start-up is given in section 4. In section 5 the results $\&$ discussion followed by conclusion of the proposed work is presented in section 6 .

\section{Health Care Startup Portfolio}
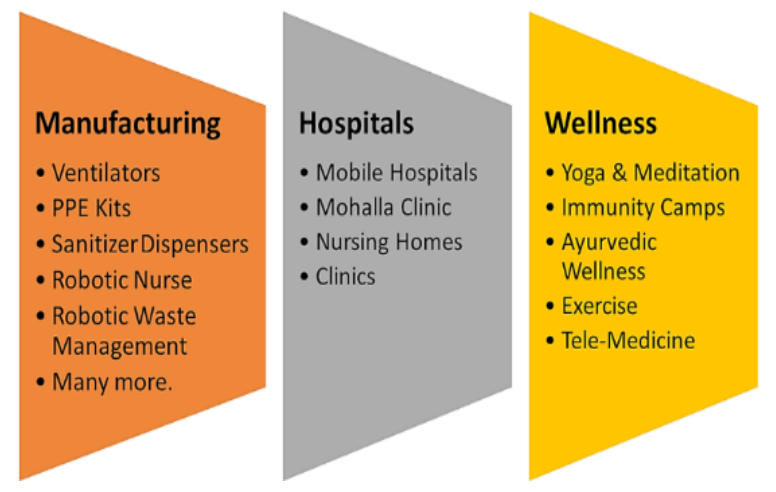

Figure I Healthcare startup portfolio.

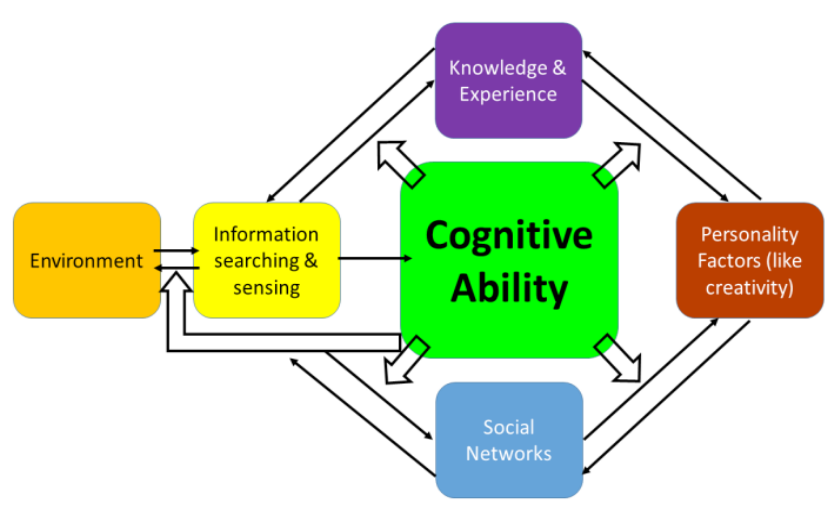

Figure 2 Entrepreneurial alertness model.

\section{Literature survey}

Li Zhao et al. ${ }^{2}$ in their paper discussed about various developments in the field of tele-medicine along with the applications of it as a portable monitoring system. ${ }^{2}$ Lorussi $\mathrm{F}$ et al. ${ }^{3}$ discussed about a specific application tele-medicine as wearable system that is 
capable of revealing the status of the motion of body parts such as hand. ${ }^{3}$ Shioda $\mathrm{Y}^{4}$ proposed a unique mechanism for providing a telemedicine system to the provision of treatment for inhabitants in rural/ remote areas. ${ }^{4}$ Chand $\mathrm{RD}$ et al. ${ }^{5}$ discussed about different schemes $\&$ projects / platform the Indian government is using as progressive communication tools for collective learning in tele-medicine \& telehealth care. ${ }^{5}$ Văleanu V et al. ${ }^{6}$ has discussed and developed a fully working prototype of portable typical tele-medicine workstation to support \& promote space assets and technological applications. ${ }^{6}$

\section{Methodology}

A keen entrepreneurial alertness is required to identify the prospective business opportunity. The prospective entrepreneurs with entrepreneur mindset require tapping in to their interest. They have to develop and explore new ways of thinking. ${ }^{7,8}$ They have to carry out SWOT (Strengths Weakness Opportunities Threats) analysis shown in Figure 3. Once they identify an opportunity it needs to be ideated and a market research is also required. ${ }^{9-12}$ Different analysis techniques are shown in Figure 4. The questionnaire-based survey technique is used to carry out the market research of the tele- healthcare start-up. Figure 5 gives the snapshot of sample survey form.

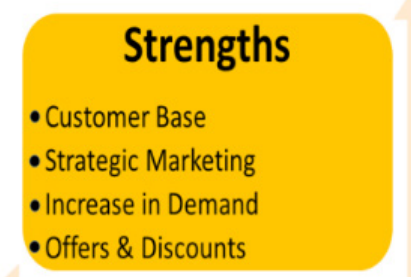

\section{Opportunities}

- Post Pandemic growth in market

- Use of indigenous method

- Evolving new market segment

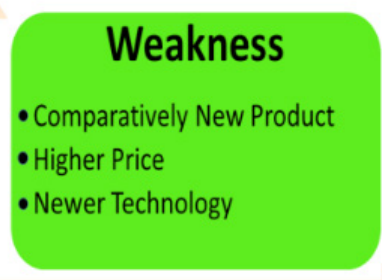

\section{Threats}

- New Brand have to earn trust of customers

- Competition with low cost imported products
Figure 3 SWOT analysis.

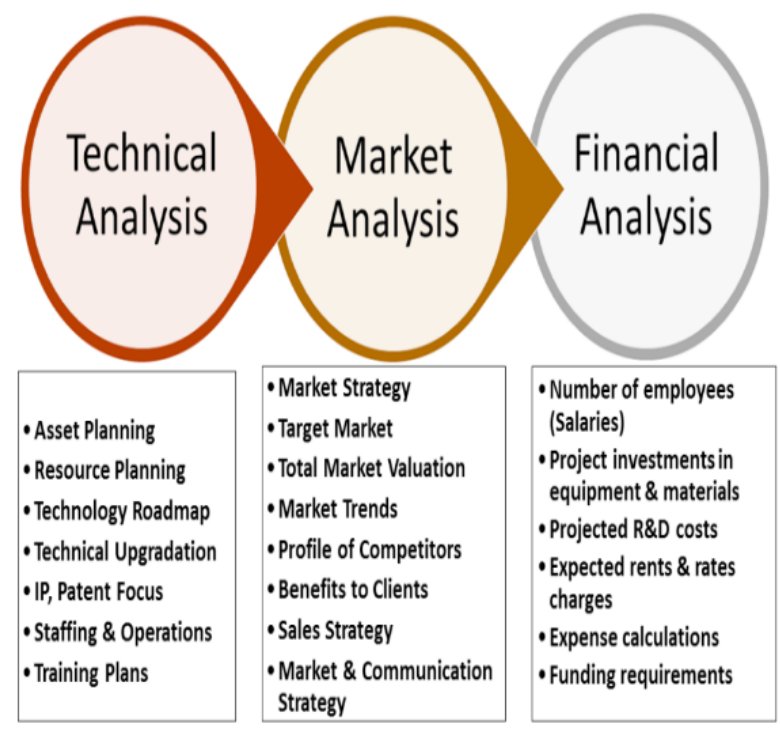

Figure 4 Different analysis techniques.

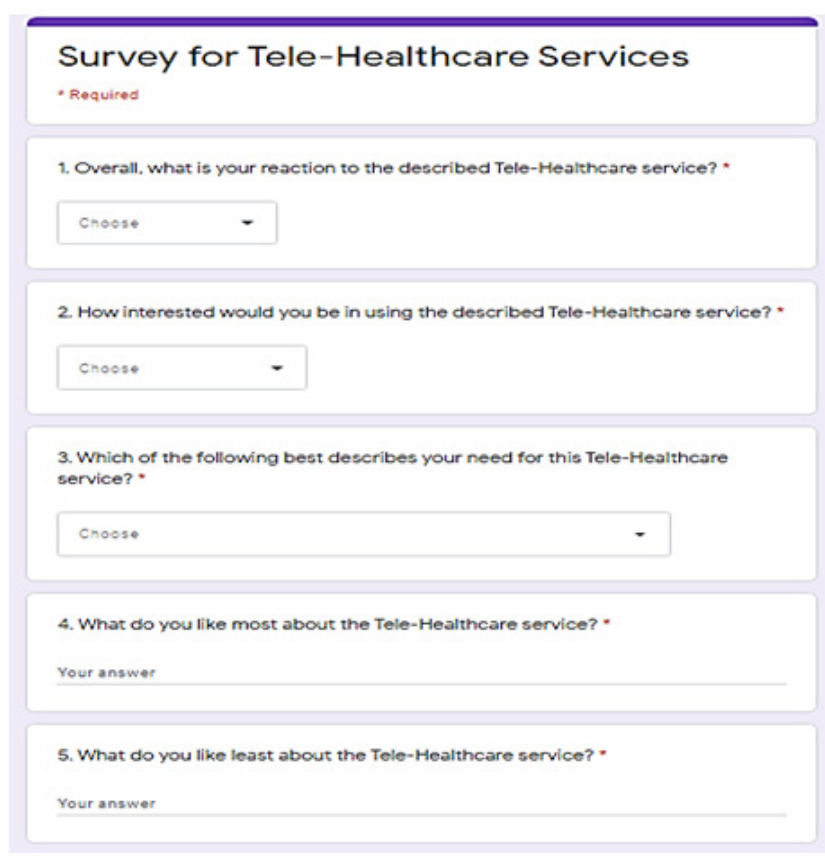

Figure 5 Snapshot of survey form.

\section{Analysis of the business model of telehealth system start-up}

\section{Customer segment}

I. Post pandemic almost every other house, enterprise, office etc. will try to get telehealth system.

II. Customers will have need of preventing/preparing themselves from any future spread/out- break of any contagious and infectious disease and they will want to accomplish this without making frequent visits to hospitals.

III. Telehealth system will not only ensure timely detection of disease, surveillance, ensure situational awareness alerts but will also provide tele-consultation/checkup, prescriptions, diagnostic results and health advices from the doctors

IV. Delivery of medicines through drones and health tips, prescriptions, diagnostic reports through mails or messages on smartphones.

\section{Value proposition}

a) Focuses on:

a. Easy to install and operate, hand held system and app/software

b. Plug and play operation

c. Can be used with smartphones as well as laptops/PCs

d. Disease detection

e. Surveillance

f. Situational awareness alerts

g. Tele-consultation/checkups

h. Health tips, prescriptions, diagnostic reports through mails or messages on smartphones. 
b) Affordable packages.

c) Handy and easy to use equipment.

d) Delivery of medicines through drones

The key feature of the setup will be delivery of medicines through robotic drones. A robotic drone prepared for the startup is shown in Figure 6. The Key features of this robotic drone telehealth service will be:

A. Delivery of medicines in the areas that are sealed and are in containment zone. It is observed that once a patient is found in any area, government officials seal that area and declare it as containment zone, to restrict the movement of residents and check the spread of the disease. Due to this many times residents of that area faces a problem and even suffer trauma due to shortage of medicine. The system shown in Figure 6 can deliver medicines in such containment areas.

B. Delivery of essential syringe, diabetes pen, remote oxygen level monitoring etc. is also possible.

C. Sanitization of suspected areas or contamination prone areas through sprayers attached on drone as shown in Figure 7.

D. Surveillance and monitoring of containment areas through cameras mounted on drones.

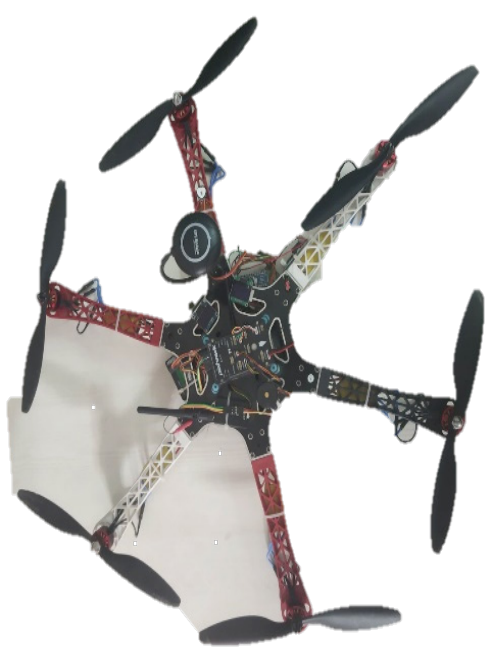

Figure 6 Robotic drone for tele-healthcare.

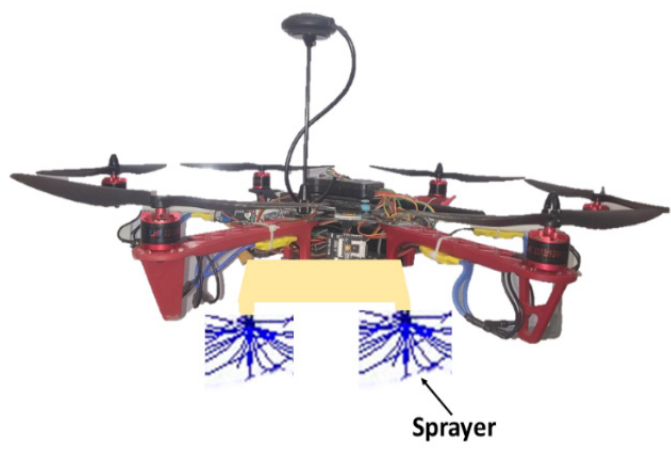

Figure 7 Robotic drone customized for sanitization using sprayer.

\section{Marketing}

Through social media such as Facebook, WhatsApp, Twitter, Instagram etc., effective use of print and visual media, pamphlets, hoardings and mouth to mouth publicity.

\section{Customer relations}

1. Special offers for yearly subscribers of telehealth services.

2. Discount packages for long duration packs of more than one year.

3. Special offers for life membership.

4. Revenue System

5. Selling subscription of telehealth services consisting of

a. deployment and training of equipment

b. installation of software

c. six months free of cost service, training and support

6. Charging fee for service after grace period.

\section{Key activities}

I. Developing and manufacturing the tele-alert system

II. Continuous feedback from customers and improving the design accordingly

III. Promoting sales and providing after sale services

IV. Separate section for liaisoning with the hospitals for teleconferencing and medical stores for tele-delivery of medicines

V. Creating and developing brand value through publicity and marketing

VI. Sales advertising and marketing

\section{Key resources}

i. Manufacturing unit and software development

ii. Funds to make initial prototype and marketing

iii. Tie-ups with hospitals and medical shops

iv. Acquiring necessary permission from the government departments

v. Acquiring certification is to make brand value and earn trust of customers

vi. Tie-ups with local District industries Centers for availing loans schemes and funds

vii. Membership of local industry associations

viii. Ensuring necessary safety and environment health certification and following standard norms and procedures

\section{Key partners}

1. Hospitals

2. Nursing homes

3. Medical stores

4. Software developers

5. Embedded system design engineers

\section{Cost structure}

a) Site cost building or industry rental

b) Manufacturing and software development equipments 
c) Material costs

d) Initial wages

\section{Results and analysis}

a. From the survey it is evident that people are interested in subscribing tele-health services and post pandemic times. Figure 6- Figure 9 gives the survey results.

b. The paper explores a special case of entrepreneurial alertness for exploring situational opportunities by presenting a case of telehealth start-up.

c. This paper explores and evaluates the proposed startup model and also presents a clear idea of Start-up ideation, formulation, development and marketing.

d. A complete feasibility study of the Start-up model is presented which includes financial aspects, marketing aspects, calculating working capital, cost of project, profitability and breakeven parameters (Figure 10 \& Figure 11).

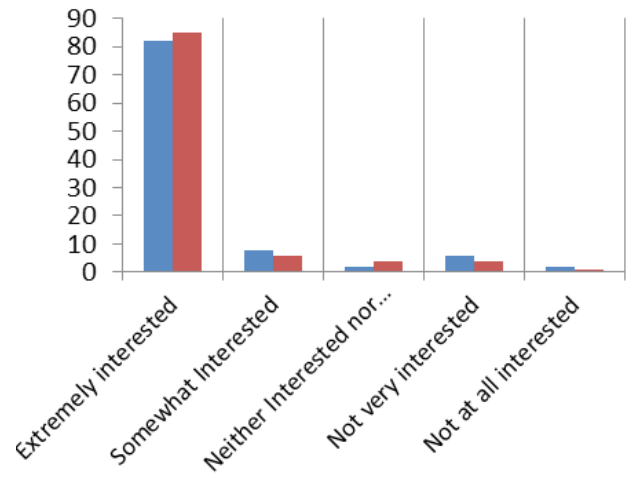

How interested would you be in using the described TeleHealthcare service?

- Overall, how interested are you in buying this TeleHealthcare service?

Figure 8 Response of people for Tele healthcare services.

\section{How often could you find a use for this Tele-Healthcare service?}

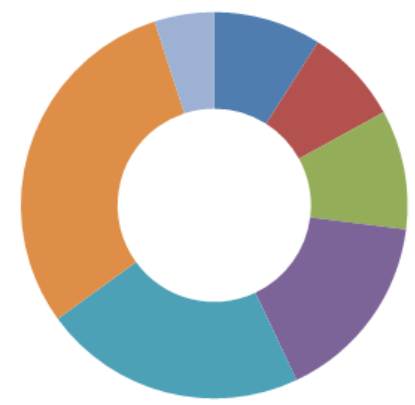

Once a week or more often

2-3 times a month

once a month

Every 2-3 months

Figure 9 Response of people about the frequency of availing tele healthcare services.

Which of the following best describes your need for this Tele-Healthcare service?

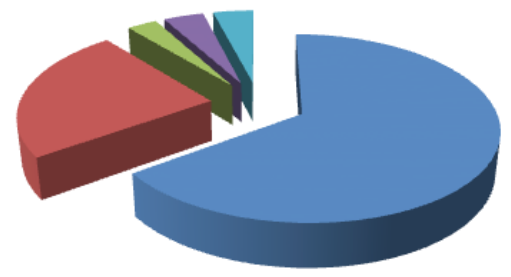

I do need it because nothing else can solve this problem

- This is just a minor improvement over what I currentiy use

In This is about the same as what I currentiy use

My current Tele-Healthcare service would serve me better

- I don't see any reason why I should buy this Tele-Healthcare service

Figure I 0 Survey result of people requirements of tele healthcare services.
Overall, what is your reaction to the described Tele-Healthcare service?

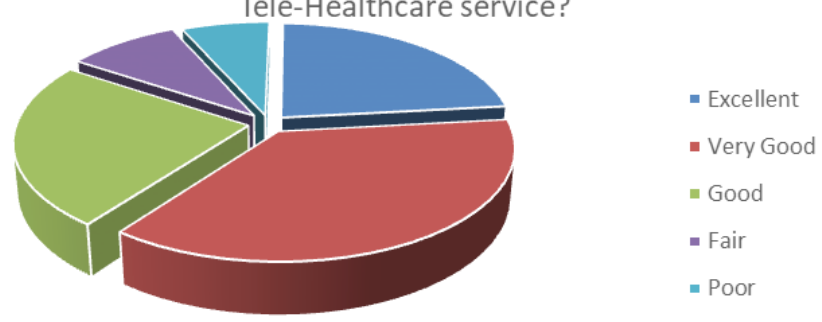

Figure I I Public response for adopting Tele healthcare services.

\section{Conclusion}

Post pandemic the total market for Tele-health system is expected to grow at a very rapid pace. Also there is an estimation that every other house in urban areas may subscribe to Tele-healthcare service by the end of year 2020. From the results \& discussion section it is evident that the healthcare sector will become one of the dominant market player. Therefore, looking into wide potential for growth of Tele-health services, for creative prospective entrepreneurs with entrepreneurial alertness, it is a big opportunity to launch a start-up. They can easily grab the opportunity to grow their business pan India along with doing their social responsibility by serving the community and nation. By launching start-up early there is a complete chance of capturing a large market share and make a huge customer base. Being one of the early players the start-up will have a very less or almost no competition. Therefore, the proposed start-up will have a full chance to grow and expand all across the country and in future after becoming a recognized brand extend its range of healthcare products.

\section{Acknowledgments}

We owe our sincere feelings of gratitude to MIT Group of Institutions, Moradabad. We are also thankful to Prof. Rohit Garg, Director MIT. We also wish to acknowledge the motivation and support provided by Entrepreneurship Development Institute of India (EDII), Ahmadabad and National Institute for Entrepreneurship \& Small Business Development (NIESBUD), Noida.

\section{Conflicts of interest}

The authors declare that there is no conflict of interest.

\section{References}

1. Lalit Sharma. A systematic review of the concept of entrepreneurial alertness. 2019.

2. Li Zhao, Yanzhen Ma, Genghuang Yang, et al. Research on development and application of Tele-medicine. 2010 International Conference on Computer and Communication Technologies in Agriculture Engineering; Chengdu. 2010. p. 347-350.

3. Lorussi F, Scilingo EP, Tesconi A, et al. Wearable sensing garment for posture detection, rehabilitation and tele-medicine. 4th International IEEE EMBS Special Topic Conference on Information Technology Applications in Biomedicine; 2003; Birmingham, UK. 2003. p. 287-290.

4. Shioda Y. Tele-medicine network employing P-P mini-microwave system with high capacity for rural and remote areas in developing countries. Proceedings. 6th International Workshop on Enterprise Networking and Computing in Healthcare Industry - Healthcom 2004 (IEEE Cat. No.04EX842); Odawara, Japan. 2004. p. 195-199.

5. Chand RD, Kumar A, Kumar A, et al. Advanced Communication Technologies for Collaborative Learning in Telemedicine and Tele-care. 2019 9th International Conference on Cloud Computing, Data Science \& Engineering (Confluence); Noida, India. 2019. p. 601-605. 
6. Văleanu V, Vladimir Vasiliu, Cristian Vizitiu, et al. Portable telemedicine workstation full prototype for technological transfer in critical interventions services. 2015 E-Health and Bioengineering Conference (EHB); Iasi. 2015. p. 1-4.

7. Kshitij Shinghal, Amit Saxena. Entrepreneurship Opportunities Innovations and Ecosystem. International Journal of Advances in Engineering \& Technology (IJAET). 2019;12(6):99-103.

8. Kshitij Shinghal, Amit Saxena. Analysis of Entrepreneurial Mindset in Engineering Students. International Journal of Advances in Engineering \& Technology (IJAET). 2020;13(1):13-23.
9. Kshtij Shinghal, Amit Saxena. Developing Entrepreneurial Mindset in Engineers. International Journal of Scientific Research and Management Studies (IJSRMS). 2017;4(2):56-59.

10. Kshtij Shinghal, Amit Saxena. Effective Entrepreneurship Education through Teaching Case. International Journal of Engineering Sciences \& Emerging Technologies. 2018;10(3):82-84.

11. Kshitij Shinghal, Amit Saxena. Importance of Nurturing Entrepreneurship Skills in Students. International Journal of Recent Trends in Electrical \& Electronics Engg. (IJRTE). 2018;7(1):13-16.

12. Healthcare Industry in India. 